\title{
Clinical and metabolic indicators associated with early mortality at a milk-fed veal facility: A prospective case-control study
}

\author{
D. L. Renaud, T. F. Duffield, S. J. LeBlanc, D. B. Haley, and D. F. Kelton ${ }^{1}$ \\ Department of Population Medicine, University of Guelph, Ontario, Canada N1G 2W1
}

\begin{abstract}
Antimicrobial use and resistance, in combination with high levels of mortality, are important challenges facing the veal industry. To improve both the economic sustainability of the industry and animal welfare, measures need to be taken to explore and address reasons for these challenges. Health status at arrival may be an important predictor of calf mortality because substantial mortality occurs early in the growing period on veal operations. The objective of this observational case-control study was to identify clinically measurable variables and metabolic indicators associated with mortality in the first $21 \mathrm{~d}$ following arrival at a veal facility. Calves were evaluated using a standardized health scoring system, blood was collected, calves were weighed, and the supplier of the calf was recorded at arrival. The calves were followed until death or $21 \mathrm{~d}$ after arrival. Cases were defined as calves that died $\leq 21$ d following arrival. Two controls for every case were randomly selected from calves that survived $>21 \mathrm{~d}$, arrived on the same day, and were housed in the same barn as cases. Stored serum harvested at arrival from cases and controls was submitted for measurement of concentrations of nonesterified fatty acids, $\beta$-hydroxybutyrate, glucose, cholesterol, urea, haptoglobin, and immunoglobulin G. A conditional logistic regression model was built to evaluate factors associated with mortality $\leq 21 \mathrm{~d}$ following arrival. A total of 4,825 calves were evaluated from November 2015 to September 2016. The mortality risk in the first $21 \mathrm{~d}$ was $2.8 \%$, giving 135 cases, which were compared with 270 controls. Six variables were significant in the final multivariable model. Calves with a slightly enlarged navel with slight pain or moisture, and those with severe dehydration had increased odds of mortality $\leq 21 \mathrm{~d}$ following arrival. Drover-derived calves, calves that weighed more, and calves that had higher concentration of immunoglobulin G or cholesterol at arrival were less likely to die. The results demonstrate that calves at elevated risk for early mor-
\end{abstract}

Received October 24, 2017.

Accepted November 28, 2017.

${ }^{1}$ Corresponding author: dkelton@uoguelph.ca tality can be identified at arrival using both health and hematological factors. Early recognition of high-risk calves may allow for an intervention that could result in improvement in survival rates; however, prevention of these abnormalities before arrival at veal facilities needs to be further explored.

Key words: antimicrobial use, veal industry, calf health status, case-control study

\section{INTRODUCTION}

Calf morbidity and mortality represent a significant cost to calf-rearing industries (Mohd Nor et al., 2012) and an important concern for animal welfare (OrtizPelaez et al., 2008). With mortality ranging from 5 to $8 \%$ in conventional veal housing (Pardon et al., 2012a; Winder et al., 2016) and $4 \%$ in animal welfare-specific housing (Bähler et al., 2012; Lava et al., 2016), there is a clear need to address its occurrence. The intensive use of antimicrobials is another important challenge faced by the veal industry (Pardon et al., 2014). In Europe, the veal calf sector uses high levels of antimicrobials (Pardon et al., 2012b; Bos et al., 2013; Lava et al., 2016); however, in Canada and the United States, the amounts used are unknown. The level of antibiotic use in the veal industry has been associated with the emergence of antimicrobial resistance in commensal, pathogenic, and zoonotic bacteria (Catry et al., 2007, 2016; Cook et al., 2011). This highlights the urgent need for change in the veal industry (CVMP-BIOHAZ, 2017), but for the industry to remain viable, controllable risk factors need to be identified and modified to decrease morbidity and mortality.

Because most mortality occurs during the early portion of the growing period, this may provide an initial area of focus (Pardon et al., 2012a; Winder et al., 2016). Health status and weight upon arrival at a veal facility can aid in the prediction of mortality early in the growing period (Bähler et al., 2012; Winder et al., 2016; Renaud et al., 2018). However, metabolic indicators may also play a role in identification of calves that are at increased risk of morbidity or mortality.

Colostrum management could be a key factor contributing to calf losses in male calf rearing (Godden, 
2008). Immunoglobulin $\mathrm{G}$ and total protein can both be used as markers for colostrum intake, with IgG being more specific in identifying failure of passive transfer (Weaver et al., 2000). Currently, the only tests that directly measure serum IgG are ELISA and radial immunodiffusion (Weaver et al., 2000). However, given the semiquantitative nature of the ELISA, radial immunodiffusion is the gold standard test (Fecteau et al., 2013). Failure of passive transfer is a common problem in male calves (Trotz-Williams et al., 2008; Pardon et al., 2015), and a strong association between serum IgG concentration and morbidity in male calves has been found (Pardon et al., 2015). However, a clear link between IgG status and mortality has not yet been established in the veal industry.

The acute phase response is a nonspecific reaction that occurs in response to tissue injury and leads to the production of acute phase proteins. Haptoglobin is an acute phase protein that increases in serum during bacterial and viral disease (Gånheim et al., 2007). It has been used to identify calves with pneumonia (Angen et al., 2009) and as a prognostic tool for calves with diarrhea (Hajimohammadi et al., 2011). Upon arrival of calves at a veal facility, the level of alpha-2 globulins - of which haptoglobin is a fraction - has been shown to affect neonatal calf diarrhea and average daily gain (Pardon et al., 2015). As the concentration of haptoglobin is low in healthy calves (Gånheim et al., 2003), it could be used as a screening tool to identify diseased calves soon after arrival at a veal facility.

Improved energy status protects against disease and supports immune function (Todd et al., 2017). It has been reported that $17 \%$ of surveyed Canadian dairy source farms providing inferior nutrition to male calves compared with female calves (Renaud et al., 2017), and this, combined with the energy expenditure and mobilization occurring during calf transport (Knowles et al., 1999), means that many male calves enter the veal industry with suboptimal energy status and low body fat cover (Wilson et al., 2000). Serum concentrations of BHB, nonesterified fatty acids (NEFA), cholesterol, glucose, and urea could all serve as markers of energy status in calves.

The objective of this study was to identify clinically measurable health and metabolic indicators associated with mortality occurring in the first $21 \mathrm{~d}$ following arrival at a veal facility.

\section{MATERIALS AND METHODS}

This observational case-control study was conducted in cooperation with a single milk-fed veal calf producer and in accordance with the University of Guelph Animal Care Committee (Animal Use Protocol: \#3453).
The producer had 5 barns in different geographical locations in southwestern Ontario, Canada. The diet provided to the calves did not differ by barn but there were several management differences. Barns 1, 2, and 4 fed calves manually, whereas barns 3 and 5 used automated calf feeders. Calves were housed individually in barns 1 and 4 and in groups of 60 calves in barns 3 and 5 . Barn 2 housed calves in individual pens in early life, transitioning to groups of 8 calves at 5 to $6 \mathrm{wk}$ following arrival.

\section{Data Collection}

When calves arrived at the receiving facility, they were immediately evaluated using a standardized health scoring system and weighed with a digital weighing scale (Cardinal Scale Manufacturing Co., Webb City, MO). The supplier of the calf and arrival date were also recorded. The suppliers were placed into 3 categories: local, drover, and auction. "Local" refers to dairy farmers who delivered calves directly to the veal facility. "Drover" refers to calves transported from multiple dairy farms to the veal facility and "auction" were calves derived from auction facilities. Calves were identified on arrival based on their Canadian Cattle Identification Agency ear tag using a handheld radiofrequency ID (RFID) reader. Mortalities occurring during the growing period were recorded using an electronic recording database (Trax-IT; Merit-Trax Technologies, Mount Royal, Quebec, Canada).

\section{Standard Health Scoring System}

An iPad (Apple Inc., Cupertino, CA) with the Calf Health Scorer app (University of Wisconsin-Madison, Madison, WI) and Qualtrics software (http://www .qualtrics.com/) was used to facilitate the health scoring. The Calf Health Scorer app provided images and descriptions to evaluate the respiratory system (nose, eye, ear, cough; McGuirk and Peek, 2014), fecal consistency (McGuirk, 2008), navel inflammation (adapted from Fecteau et al., 1997), joint swelling, and rectal temperature. A Qualtrics form was used to collect data on the evaluation of dehydration (Wilson et al., 2000), BCS (Wilson et al., 2000), and sunken flank (Bähler et al., 2012; Table 1). All calves were examined by 1 of 3 observers; however, all case and control triads were evaluated by the same observer.

\section{Blood Collection and Processing}

Following the health examination, approximately 10 $\mathrm{mL}$ of whole blood was collected from the jugular vein into a sterile blood collection tube without an antico- 
DAIRY INDUSTRY TODAY

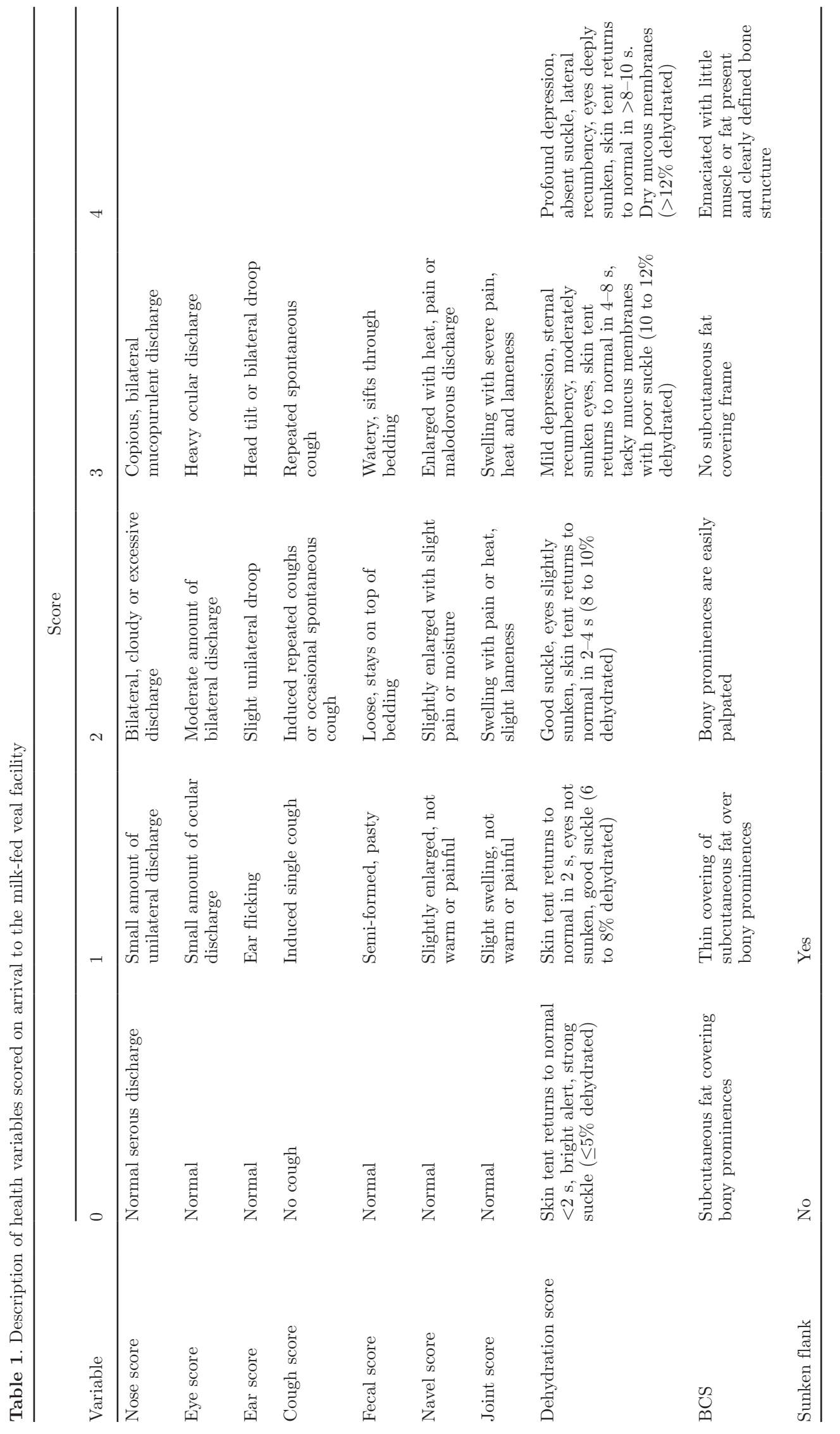


agulant (BD Vacutainer, Becton, Dickinson and Co., Franklin Lakes, NJ). Blood was transported on ice to the laboratory, where it was allowed to clot and then centrifuged at $1,500 \times g$ for $15 \mathrm{~min}$ at approximately $20^{\circ} \mathrm{C}$. The approximate time from blood collection until centrifugation of the blood was $3 \mathrm{~h}$. Serum was separated and stored at $-20^{\circ} \mathrm{C}$ until submission to the Animal Health Laboratory (Guelph, ON, Canada) and Saskatoon Colostrum Company (Saskatoon, SK, Canada) for further analysis. Serum from cases and controls was analyzed for NEFA, BHB, glucose, cholesterol, urea, haptoglobin, and IgG. The biochemistry testing was done on the Roche Cobas 6000 c501 automated chemistry analyzer (Roche Canada, Laval, QC, Canada). Concentrations of NEFA and BHB were measured using Randox NEFA and Randox BHBA kits (Randox Laboratories Canada Ltd., Mississauga, ON, Canada). Glucose concentration was determined using the Roche GLU3 kit (Roche Canada) whereas cholesterol concentration was determined using the Roche CHOL2 kit (Roche Canada). The Roche UREAL kit (Roche Canada) was used to measure urea concentrations. Haptoglobin concentrations were measured by determining the hemoglobin binding capacity of serum, which was quantified against a standard sample (Skinner et al., 1991). Serum IgG was determined by radial immunodiffusion as described by Chelack et al. (1993).

\section{Selection of Cases and Controls}

A calf was selected as a case if it died $\leq 21 \mathrm{~d}$ after arriving at the facility. The 21-d cutpoint was selected based on previous work that demonstrated that a significant proportion of mortality occurred in the first 3 wk after arrival at veal calf facilities (Bähler et al.,
2012; Pardon et al., 2012a; Winder et al., 2016). Two controls for each case were randomly selected from calves that survived $>21 \mathrm{~d}$, arrived on the same day, and were housed in the same barn as the cases. Two controls were used to improve the precision of the association estimates (Dohoo et al., 2010a). All calves selected were male.

\section{Statistical Analysis}

All statistical analyses were completed using Stata 14 (StataCorp LP, College Station, TX). Data were imported from Excel (Microsoft Corp., Redmond, WA) into Stata 14 and checked for completeness. Calves with missing data were deleted from analysis (complete-case analysis; Pigott, 2001). A causal diagram was created to evaluate the relationship between mortality and the measured variables (Figure 1). Descriptive statistics were generated for all explanatory variables in the data set.

Blood measures of cases and controls were summarized to describe characteristics of both groups. A Student's $t$-test was used to identify significant $(P \leq 0.05)$ differences between cases and controls for normally distributed parameters and a Kolmogorov-Smirnov test was used for non-normally distributed parameters. All blood parameters had normal distributions except $\mathrm{BHB}$, haptoglobin, and urea.

A single conditional logistic regression model was built to explore associations with mortality $\leq 21 \mathrm{~d}$ following arrival. The assumption of linearity of continuous predictor variables was assessed by plotting the logarithmic odds of the outcome against the variable. If a variable failed to meet the linearity assumption, the variable was categorized into 2 categories. Concentrations of

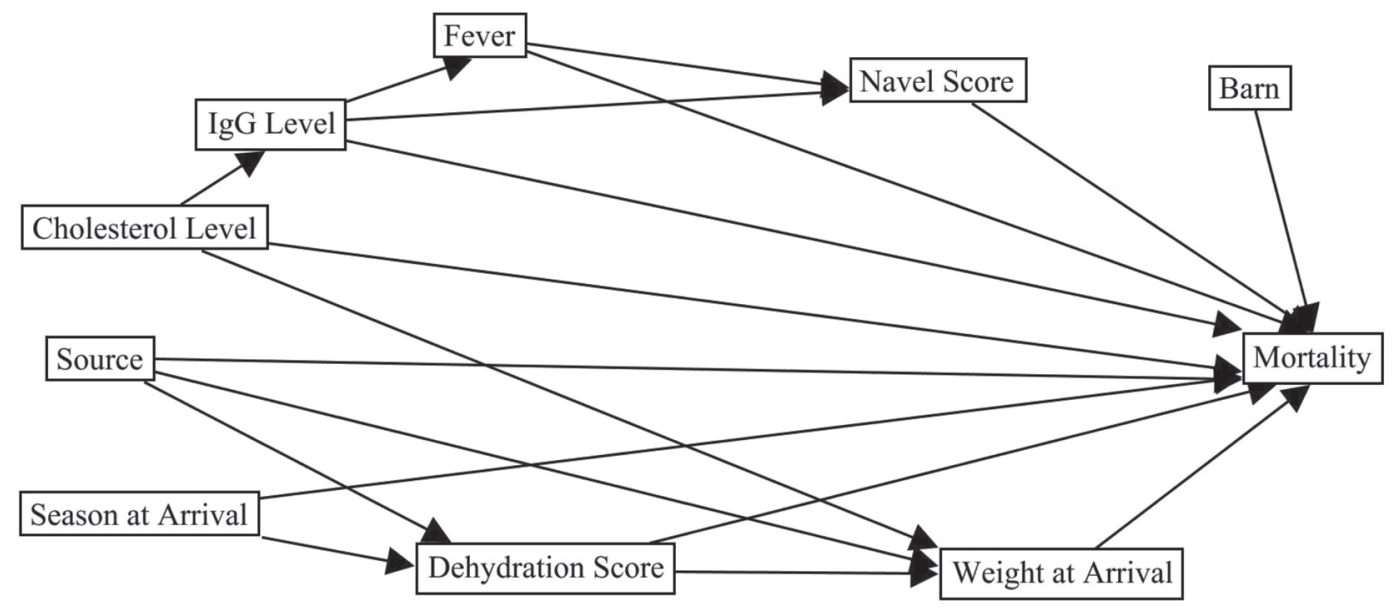

Figure 1. Causal diagram describing the hypothesized relationship of measured variables to mortality occurring during the first $21 \mathrm{~d}$ of the growing period at a milk-fed veal calf facility in Ontario. 
NEFA, haptoglobin, and BHB were categorized based on cutpoints generated by the Youden Index (Youden, 1950). The Youden Index is a summary measure of the receiver operator characteristic (ROC) curve, measuring the accuracy of a diagnostic marker and generating an optimal cutpoint for the marker (Fluss et al., 2005). Collinearity among the explanatory variables was tested using Spearman rank coefficients. If the correlation coefficient between 2 variables was $\geq 0.6$, only 1 variable was retained based on fewest missing values, reliability of measurement, or biological plausibility. Univariable logistic regression models were constructed to identify variables that were unconditionally associated with the outcome using a $P$-value of 0.2 . Risk factors that had univariate associations $(P<0.2)$ were subsequently offered to a multivariable model through a manual backward stepwise process. Variables were retained in the multivariable models if $P<0.05$. Evaluating the effect of the removed variables on the coefficients of the remaining variables was used to assess confounding. A variable was deemed a confounder if it was not an intervening variable based on the causal diagram (Figure 1), and the log odds of a significant variable in the model changed by at least $20 \%$. Two-way interactions were evaluated between variables suspected to interact based on evidence from the literature and remained in the final model if significant $(P<0.05)$ (Dohoo et al., 2010b). Outliers were identified and evaluated using Pearson residuals and deviance residuals as well as delta-betas, case-control group delta-betas, delta- $\chi^{2}$, and case-control group delta- $\chi^{2}$ (Dohoo et al., 2010c). If outliers were found, they were explored to determine the characteristics of the observations that made them outliers. The outliers were retained in the analysis unless the magnitude and direction of the coefficients in the final model were altered by the removal of the data points or if the data were found to be erroneous.

For continuous metabolic indicators in blood that were significant in the final multivariable model and linearly associated with logarithmic odds of the outcome, a Youden's Index (Youden, 1950) was used to determine cutpoints.

\section{RESULTS}

\section{Descriptive Statistics}

In total, 4,825 calves were evaluated from November 2015 to September 2016; 135 cases died $\leq 21$ d following arrival, representing a mortality risk of $2.8 \%$ and encompassing $38 \%(135 / 357)$ of the overall mortality occurring in the facility. A total of 270 controls were randomly selected using the criteria previously described. The majority (43\%) of case and control calves arrived at the facility in the summer months (June to August) with 26, 25, and 6\% arriving in the spring (March to May), winter (December to February), and fall (September to November), respectively. The calves were assigned to the 5 barns based on the availability of rooms within the barn. Barns 1, 2, 3, 4, and 5 housed $27,28,35,7$, and $4 \%$ of the calves, respectively. The calves were derived from 120 sources, which were categorized into 3 main groups. Local, drover, and auction-derived calves represented 21,66 , and $13 \%$ of the overall population, respectively.

\section{Health Parameters}

Table 2 describes the proportion of cases and controls with specific health attributes. A $\chi^{2}$ value was calculated for each health attribute to identify statistically significant differences between the case and control groups (Table 2). Dehydration and emaciation were present in 50 and $54 \%$ of calves at arrival, respectively. Approximately a quarter of calves entered the facility with an abnormal navel score or fecal score. A calf seldom entered the facility with an abnormality in the respiratory or joint parameters. Rectal temperature (Table 3) did not differ numerically between cases and controls. Three observers evaluated all the calves upon arrival, with observers 1,2 , and 3 examining 40, 45, and $15 \%$ of the case-control groups, respectively.

\section{Blood Parameters}

We detected significant differences between cases and controls in weight at arrival, and serum BHB, glucose, cholesterol, and IgG (Table 3). A total of $14(10 \%)$ cases and $6(2 \%)$ controls were hypoglycemic $(<3.3$ $\mathrm{mmol} / \mathrm{L}$; Smith, 2009). Based on the Youden Index, haptoglobin was cut at $0.18 \mathrm{~g} / \mathrm{L}$ (sensitivity: 0.67; specificity: 0.39; area under the curve: 0.51 ); NEFA was cut at $0.35 \mathrm{mmol} / \mathrm{L}$ (sensitivity: 0.67 ; specificity: 0.39 ; area under the curve: 0.53 ); and BHB was cut at 60.50 $\mu \mathrm{mol} / \mathrm{L}$ (sensitivity: 0.34; specificity: 0.55 ; area under the curve: 0.45$)$.

\section{Early Mortality Model}

The variables unconditionally associated with early mortality are given in Table 4 . In the final multivariable model, 6 variables were significant (Table 5). A navel score of 2 and dehydration scores of 4 and 5 were associated with higher odds of mortality. Droverderived calves, greater weight at arrival, and a greater concentration of IgG or cholesterol were associated with lower odds of mortality. No interactions were identified in the final model. A single match group outlier 
Table 2. Frequency distribution (\%) of calf health attributes scored on arrival at a milk-fed veal facility for 135 calves that died $\leq 21 \mathrm{~d}$ following arrival to a milk-fed veal facility (case) and 270 calves that survived $>21 \mathrm{~d}$ following arrival to a milk-fed veal facility (control)

\begin{tabular}{|c|c|c|c|c|c|c|c|}
\hline \multirow[b]{2}{*}{ Variable } & \multirow[b]{2}{*}{ Calf } & \multicolumn{5}{|c|}{ Score } & \multirow[b]{2}{*}{$\chi^{2}(P$-value $)$} \\
\hline & & 0 & 1 & 2 & 3 & 4 & \\
\hline Nasal score & Control & 76 & 24 & 0 & 0 & - & \\
\hline \multirow[t]{2}{*}{ Eye score } & Case & 70 & 27 & 2 & 0 & - & 0.49 \\
\hline & Control & 65 & 33 & 2 & 0 & - & \\
\hline Cough score & Case & 90 & 7 & 3 & 0 & - & 0.02 \\
\hline Fecal score & Control & 68 & 21 & 8 & 3 & - & \\
\hline \multirow[t]{2}{*}{ Navel score } & Case & 19 & 47 & 23 & 11 & - & 0.17 \\
\hline & Control & 21 & 55 & 17 & 6 & - & \\
\hline \multirow[t]{2}{*}{ Joint score } & Case & 98 & 1 & 0 & 2 & - & 0.05 \\
\hline & Control & 100 & 0 & 0 & 0 & - & \\
\hline \multirow[t]{2}{*}{ BCS } & Case & 1 & 7 & 41 & 35 & 16 & 0.78 \\
\hline & Control & 2 & 8 & 34 & 39 & 17 & \\
\hline
\end{tabular}

was identified; however, it was not determined to be a recording error and was retained in the final model as the magnitude and direction of the coefficients did not change. Cutpoints generated by Youden's Index for continuous variables that were significant in the final model and linearly associated with logarithmic odds of the outcome are presented in Table 6 .

\section{DISCUSSION}

This study demonstrated that serum IgG and cholesterol concentrations were associated with increased risk for mortality in the first $21 \mathrm{~d}$ following arrival at a veal facility. To our knowledge, this is the first study to identify cholesterol as a marker for mortality in calves arriving at a veal facility. However, creating cutpoints for IgG and cholesterol yielded poor estimates of sensitivity and specificity, suggesting that, as standalone tests, both parameters are poor at identifying calves at high risk for early mortality and it may not be economical to use these tests practically. Health status at arrival, specifically navel score and degree of dehydration, were predictors of mortality occurring in the first $21 \mathrm{~d}$ following arrival. Source of the calves and weight on arrival were associated with early mortality. A limitation to this study was the length of time from blood

Table 3. Weight, rectal temperature, and metabolic parameters for 135 calves that died $\leq 21 \mathrm{~d}$ following arrival to a milk-fed veal facility (case) and 270 calves that survived $>21 \mathrm{~d}$ following arrival to a milk-fed veal facility (control)

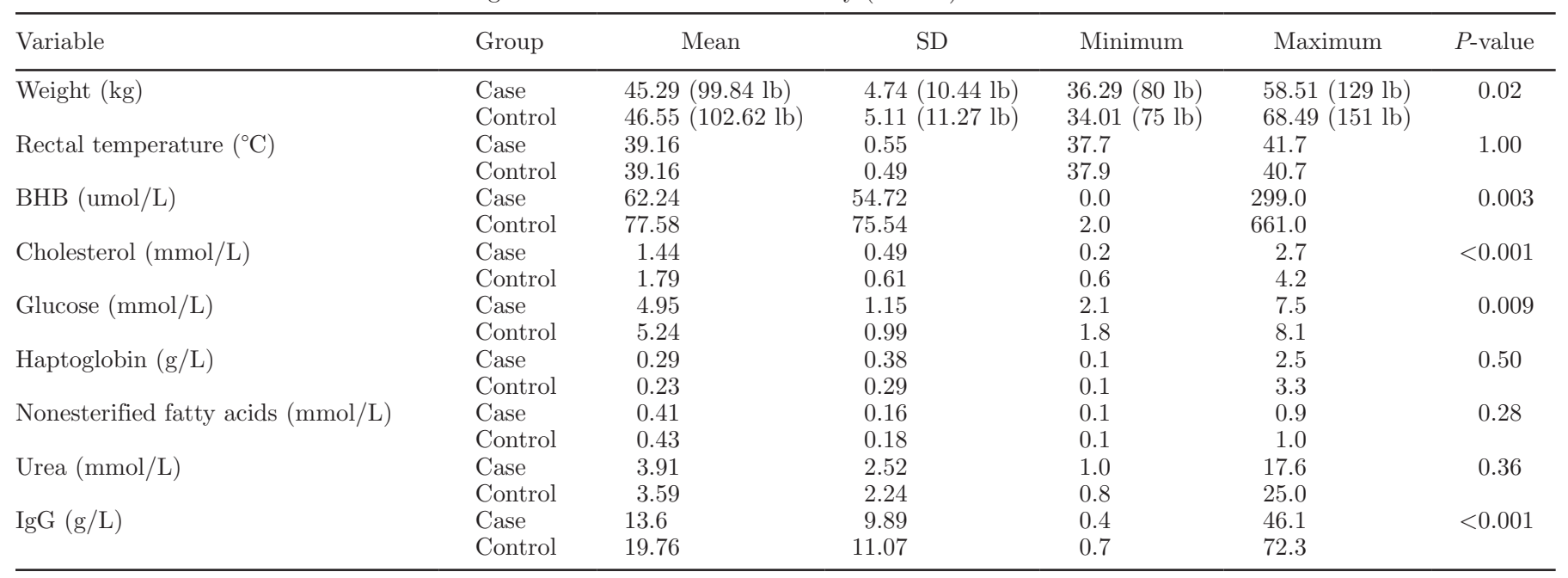


Table 4. Results of univariable conditional logistic regression model of associations of variables assessed at arrival and mortality $\leq 21 \mathrm{~d}$ after arrival at a milk-fed veal facility using data from 135 case calves and 270 control calves

\begin{tabular}{|c|c|c|c|c|c|}
\hline Variable & Description & $\mathrm{n}$ & Odds ratio & $95 \% \mathrm{CI}$ & $P$-value \\
\hline \multirow[t]{2}{*}{ Rectal temperature } & $<40^{\circ} \mathrm{C}$ & 377 & Referent & & \\
\hline & $\geq 40^{\circ} \mathrm{C}$ & 25 & 1.85 & 0.84 to 4.05 & 0.13 \\
\hline \multirow[t]{3}{*}{ Fecal score } & 0 and 1 & 345 & Referent & & \\
\hline & 2 & 39 & 1.85 & 0.90 to 3.83 & 0.09 \\
\hline & 3 & 19 & 2.44 & 0.94 to 6.30 & 0.07 \\
\hline \multirow[t]{3}{*}{ Navel score } & 0 and 1 & 296 & Referent & & \\
\hline & 2 & 78 & 1.61 & 0.93 to 2.77 & 0.09 \\
\hline & 3 & 31 & 2.21 & 1.04 to 4.70 & 0.04 \\
\hline \multirow[t]{4}{*}{ Dehydration score } & 0 & 201 & Referent & & \\
\hline & 1 & 137 & 1.88 & 1.13 to 3.12 & 0.01 \\
\hline & 2 & 53 & 2.04 & 1.00 to 4.19 & 0.05 \\
\hline & 3 and 4 & 11 & 5.83 & 1.58 to 21.41 & $<0.01$ \\
\hline \multirow[t]{2}{*}{ Sunken flank } & Yes & 98 & Referent & & \\
\hline & No & 305 & 0.65 & 0.36 to 1.18 & 0.16 \\
\hline \multirow[t]{3}{*}{ Source } & Local & 85 & Referent & & \\
\hline & Drover & 269 & 0.59 & 0.36 to 0.98 & 0.04 \\
\hline & Auction & 51 & 0.66 & 0.30 to 1.48 & 0.31 \\
\hline BW & Every $1 \mathrm{~kg}$ increase & & 0.92 & 0.87 to 0.98 & $<0.01$ \\
\hline $\operatorname{Ig} G$ & Every $1 \mathrm{~g} / \mathrm{L}$ increase & & 0.94 & 0.91 to 0.96 & $<0.01$ \\
\hline Glucose & Every $1 \mathrm{mmol} / \mathrm{L}$ increase & & 0.77 & 0.62 to 0.94 & 0.01 \\
\hline Cholesterol & Every $1 \mathrm{mmol} / \mathrm{L}$ increase & & 0.23 & 0.13 to 0.39 & $<0.01$ \\
\hline
\end{tabular}

collection until serum separation, which would lead to an underestimation of glucose levels due to the utilization of glucose by red blood cells.

The association of navel score with mortality is not a surprising finding because navel infection has been previously shown to affect mortality and overall health of calves (Donovan et al., 1998; Mee, 2008). The high prevalence of calves arriving with abnormal navel score is similar to that in the literature (Wilson et al., 2000) and demonstrates a need to further explore preventative measures for this condition. Calves that were $>10 \%$ dehydrated at arrival were at increased risk of mortality. Dehydration is also a common issue found in the veal industry (Wilson et al., 2000) and could reflect the time in transit from the source dairy farm (Knowles et al., 1997). Weight at arrival has previously been demonstrated to affect both morbidity (Brscic et al., 2012) and mortality (Winder et al., 2016) in the veal industry. It is unclear whether weight is a reflection of age or nutritional status at the source dairy farm, but it needs to be explored as a mechanism to reduce the risk of mortality. Locally derived calves had increased risk of mortality compared with drover-derived calves. As drovers were more likely to be economically penalized by the veal facility for calves in poor health, they may have implemented a screening process to select healthier calves before transportation. For a more thorough discussion on the effect of health status, weight, and source of the calves on mortality, see Renaud et al. (2018).

Table 5. Final multivariable conditional logistic regression model describing the associations among significant independent variables and the outcome early mortality ( $\leq 21 \mathrm{~d}$ after arrival at a milk-fed veal facility) using data from 135 case calves and 270 control calves

\begin{tabular}{llccr}
\hline Variable & Description & Odds ratio & $95 \%$ CI & $P$-value \\
\hline Navel score & 0 and 1 & Referent & & \\
& 2 & 2.22 & 1.10 to 4.50 & 0.03 \\
Dehydration score & 3 & 2.51 & 0.98 to 6.41 & 0.06 \\
& 1 & Referent & & \\
& 2 & 1.36 & 0.74 to 2.48 & 0.32 \\
IgG & 3 & 1.16 & 0.48 to 2.78 & 0.74 \\
BW & 4 and 5 & 6.10 & 1.12 to 33.19 & 0.04 \\
Cholesterol & Every $1 \mathrm{~g} / \mathrm{L}$ increase & 0.94 & 0.91 to 0.97 & $<0.01$ \\
Source & Every $1 \mathrm{~kg}$ increase & 0.93 & 0.86 to 1.00 & 0.04 \\
& Every 1 mmol/L increase & 0.28 & 0.16 to 0.50 & $<0.01$ \\
& Local & Referent & & \\
& Drover & 0.48 & 0.25 to 0.93 & 0.03 \\
& Auction & 0.61 & 0.20 to 1.86 & 0.39 \\
\hline
\end{tabular}


Table 6. Cutpoints calculated by Youden's Index ${ }^{1}$ for $\operatorname{IgG}$, BW, and cholesterol from blood samples collected from 135 cases and 270 controls at arrival to a milk-fed veal calf facility

\begin{tabular}{llccc}
\hline Variable & Cutpoint & Se (\%) & Sp (\%) & AUC \\
\hline IgG (g/L) & $\geq 16.7$ & 34 & 49 & 0.45 \\
BW (kg) & $\geq 46.49$ & 36 & 54 & 0.41 \\
Cholesterol (mmol/L) & $\geq 1.6$ & 36 & 40 & 0.38 \\
\hline
\end{tabular}

${ }^{1}$ Se (sensitivity) was defined as the proportion of cases (died $<21 \mathrm{c}$ after arrival) having a test result above the cutpoint; Sp (specificity) was defined as the proportion of controls (survived $>21 \mathrm{~d}$ after arrival) having a test result below the cutpoint; AUC (area under the curve) was the probability that a randomly selected case had a greater score than a randomly selected control.

Calves depend almost entirely on the absorption of maternal immunoglobulins from colostrum after birth to protect against common pathogens until their own immune system reaches functional maturity (Godden, 2008). Thus, it is expected that the higher the concentration of $\operatorname{IgG}$, the lower the risk of mortality. One of the major challenges with veal production is that veal producers rely on dairy producers to provide the necessary care of these calves on the dairy farm of origin before departure. As a minority (9\%) of Canadian dairy producers did not always feed colostrum to male calves (Renaud et al., 2017), this is an area that needs to be addressed to improve the health and welfare of male calves.

Hypoglycemia is a common metabolic derangement occurring in neonatal calves (Smith, 2009). It can occur due to generalized infection (Lofstedt et al., 1999), diarrhea (Santos et al., 2002), or the withdrawal of milk (Smith, 2009). In this study, the prevalence of hypoglycemia was higher in cases than in controls, and glucose concentrations were associated with mortality in the unconditional analysis. However, the relationship between hypoglycemia and mortality did not remain in the final regression model, suggesting that other factors were more important for predicting mortality in this study. These findings regarding glucose need to be considered in light of the serum not being separated immediately.

The association of serum cholesterol with early mortality could have multiple explanations. Cholesterol deficiency haplotype $(\mathrm{CDH})$, which results in low levels of cholesterol (Otter and Hately, 2017), causes emaciation, growth retardation, and diarrhea, leading to increased levels of mortality (Kipp et al., 2016). With the lineage of this deficiency tracing back to a prominent sire in Canada (Maughlin Storm; Kipp et al., 2016), this haplotype may be common in Canada. Cholesterol could also be used as a marker of colostrum intake. The cholesterol concentration is much higher in colostrum than in milk, and concentrations in the first days of life are proportional to the amounts of ingested colostrum (Ontsouka et al., 2016). Cholesterol in colostrum plays a critical role in mediating postnatal growth and development by influencing intestinal signaling and promotion of intestinal lactase activity, which may affect mortality and morbidity in calves (Ontsouka et al., 2016). Cholesterol concentrations in serum also increase with age (Piccione et al., 2010). As calves transported at older ages had lower mortality after transportation (Knowles, 1995), low cholesterol concentrations may represent younger calves. As multiple factors could influence cholesterol concentrations, greater understanding of the mechanisms surrounding cholesterol's influence on mortality is needed.

Concentrations of NEFA, BHB, and urea, which were used as markers of energy status, were not associated with mortality. Knowles et al. (1999) had previously found differences in long-distance transport of calves with respect to these parameters. However, in this study, it is unlikely that calves were transported or held off feed for more than $10 \mathrm{~h}$, and these effects may only have been present in calves transported for longer durations.

Haptoglobin was not a good indicator of early mortality when evaluated upon arrival. Acute phase proteins increase rapidly with the onset of clinical signs or subclinical inflammation; therefore, haptoglobin may not identify calves during a disease incubation period (Svensson et al., 2007). Haptoglobin also increases in response to stress of transportation (Lomborg et al., 2008), which may result in elevated haptoglobin concentrations. These factors could explain the poor performance of haptoglobin in identifying individual calves at increased risk for disease or death. Similar conclusions were made by Svensson et al. (2007) and Murray et al. (2014), in which haptoglobin had a poor discriminative ability to identify individual calves with or at risk for disease.

\section{CONCLUSIONS}

Assessing health and metabolic factors upon arrival at a veal facility can identify calves at risk for mortality in the first $21 \mathrm{~d}$ after arrival. Calves with low levels of cholesterol and IgG at arrival are at greater risk for early mortality. Navel score, dehydration level, source, and weight should also be evaluated to identify high-risk calves. Screening of calves upon arrival at a veal facility may allow for detection and intervention on high-risk calves to improve survival rates; however, emphasis should be placed on preventative measures, such as improved colostrum management and navel care, before arrival at the veal facility. 


\section{ACKNOWLEDGMENTS}

The authors thank the participating producer. The first author was also supported by Grober Inc. (Cambridge, ON, Canada), Veal Farmers of Ontario (Guelph, ON, Canada), Dairy Farmers of Ontario (Mississauga, ON, Canada), the Ontario Ministry of Agriculture, Food and Rural Affairs, and the Ontario Veterinary College (University of Guelph).

\section{REFERENCES}

Angen, O., J. Thomsen, L. E. Larsen, J. Larsen, B. Kokotovic, P. M. Heegaard, and J. M. Enemark. 2009. Respiratory disease in calves: Microbiological investigations on trans-tracheally aspirated bronchoalveolar fluid and acute phase protein response. Vet. Microbiol. 137:165-171. https://doi.org/10.1016/j.vetmic.2008.12.024.

Bähler, C., A. Steiner, A. Luginbühl, A. Ewy, H. Posthaus, D. Strabel, T. Kaufmann, and G. Regula. 2012. Risk factors for death and unwanted early slaughter in Swiss veal calves kept at a specific animal welfare standard. Res. Vet. Sci. 92:162-168. https://doi .org/10.1016/j.rvsc.2010.10.009

Bos, M. E. H., F. J. Taverne, I. M. van Geijlswijk, J. W. Mouton, D. J. Mevius, and D. J. Heederik. 2013. Consumption of antimicrobials in pigs, veal calves, and broilers in the Netherlands: Quantitative results of nationwide collection data in 2011. PLoS One 8:e77525. https://doi.org/10.1371/journal.pone.0077525.

Brscic, M., H. Leruste, L. Heutinck, E. Bokkers, M. Wolthuis-Fillerup, N. Stockhofe, F. Gottardo, B. Lensink, G. Cozzi, and C. V. Reenen. 2012. Prevalence of respiratory disorders in veal calves and potential risk factors. J. Dairy Sci. 95:2753-2764. https://doi.org/ 10.3168/jds.2011-4699.

Catry, B., J. Dewulf, T. Goffin, A. Decostere, F. Haesebrouck, and A. D. Kruif. 2007. Short Communication: Antimicrobial resistance patterns of Escherichia coli through the digestive tract of veal calves. Microb. Drug Resist. 13:147-150. https://doi.org/10.1089/ mdr.2007.744.

Catry, B., J. Dewulf, D. Maes, B. Pardon, B. Callens, M. Vanrobaeys, G. Opsomer, A. de Kruif, and F. Haesebrouck. 2016. Effect of antimicrobial consumption and production type on antibacterial resistance in the bovine respiratory and digestive tract. PLoS One 11:e0146488.

Chelack, B. J., P. S. Morley, and D. M. Haines. 1993. Evaluation of methods for dehydration of bovine colostrum for total replacement of normal colostrum in calves. Can. Vet. J. 34:407-412.

Cook, A., R. J. Reid-Smith, R. J. Irwin, S. A. Mcewen, V. Young, K. Butt, and C. Ribble. 2011. Antimicrobial resistance in Escherichia coli isolated from retail milk-fed veal meat from southern Ontario, Canada. J. Food Prot. 74:1328-1333. https://doi.org/10.4315/ 0362-028X.JFP-10-495.

CVMP-BIOHAZ (EMA Committee for Medicinal Products for Veterinary Use-EFSA Panel on Biological Hazards. 2017. EMA and EFSA joint scientific opinion on measures to reduce the need to use antimicrobial agents in animal husbandry in the European Union, and the resulting impacts on food safety (RONAFA). J. EFSA 15:e04666. https://doi.org/10.2903/j.efsa.2017.4666.

Dohoo, I., W. Martin, and H. Stryhn. 2010a. Case-control studies. Pages 181-198 in Veterinary Epidemiological Research. 2nd ed. VER Inc., Charlottetown, Prince Edward Island, Canada.

Dohoo, I., W. Martin, and H. Stryhn. 2010b. Model-building strategies. Pages 365-394 in Veterinary Epidemiological Research. 2nd ed. VER Inc., Charlottetown, Prince Edward Island, Canada.

Dohoo, I., W. Martin, and H. Stryhn. 2010c. Logistic regression. Pages 395-426 in Veterinary Epidemiological Research. 2nd ed. VER Inc., Charlottetown, Prince Edward Island, Canada.

Donovan, G. A., I. R. Dohoo, D. M. Montgomery, and F. L. Bennett. 1998. Associations between passive immunity and morbidity and mortality in dairy heifers in Florida, USA. Prev. Vet. Med. 34:3146. https://doi.org/10.1016/s0167-5877(97)00060-3.

Fecteau, G., J. Arsenault, J. Pare, D. C. Van Metre, C. A. Holmberg, and B. P. Smith. 2013. Prediction of serum IgG concentration by indirect techniques with adjustment for age and clinical and laboratory covariates in critically ill newborn calves. Can. J. Vet. Res. 77:89-94.

Fecteau, G., J. Pare, D. C. Van Metre, B. P. Smith, C. A. Holmberg, W. Gutterbock, and S. Jang. 1997. Use of a clinical sepsis score for predicting bacteremia in neonatal dairy calves on a calf rearing farm. Can. Vet. J. 38:101-104.

Fluss, R., D. Faraggi, and B. Reiser. 2005. Estimation of the Youden Index and its associated cutoff point. Biom. J. 47:458-472. https:// doi.org/10.1002/bimj.200410135.

Gånheim, C., S. Alenius, and K. P. Waller. 2007. Acute phase proteins as indicators of calf herd health. Vet. J. 173:645-651. https://doi .org/10.1016/j.tvjl.2006.01.011.

Gånheim, C., C. Hulten, U. Carlsson, H. Kindahl, R. Niskanen, and K. P. Waller. 2003. The acute phase response in calves experimentally infected with bovine viral diarrhoea virus and/or Mannheimia haemolytica. J. Vet. Med. B Infect. Dis. Vet. Public Health 50:183190. https://doi.org/10.1046/j.1439-0450.2003.00658.x.

Godden, S. 2008. Colostrum management for dairy calves. Vet. Clin. North Am. Food Anim. Pract. 24:19-39. https://doi.org/10.1016/ j.cvfa.2007.10.005.

Hajimohammadi, A., S. Nazifi, M. Ansari-Lari, M. R. Khoshmanzar, and S. M. Bigdeli. 2011. Identifying relationships among acute phase proteins (haptoglobin, serum amyloid A, fibrinogen, ceruloplasmin) and clinical findings in dairy calf diarrhea. Comp. Clin. Pathol. 22:227-232. https://doi.org/10.1007/s00580-011-1390-5.

Kipp, S., D. Segelke, S. Schierenbeck, F. Reinhardt, R. Reents, C. Wurmser, H. Pausch, R. Fries, G. Thaller, J. Tetens, J. Pott, D. Haas, B. Raddatz, M. Hewicker-Trautwein, I. Proios, M. Schmicke, and W. Grünberg. 2016. Identification of a haplotype associated with cholesterol deficiency and increased juvenile mortality in Holstein cattle. J. Dairy Sci. 99:8915-8931. https://doi.org/10.3168/ jds.2016-11118.

Knowles, T. G. 1995. A review of post transport mortality among younger calves. Vet. Rec. 137:406-407. https://doi.org/10.1136/ vr.137.16.406.

Knowles, T. G., G. Warriss, S. Brown, J. Edwards, P. Watkins, and A. Phillips. 1997. Effects on calves less than one month old of feeding or not feeding them during road transport of up to 24 hours. Vet. Rec. 140:116-124.

Knowles, T. G., S. N. Brown, J. E. Edwards, A. J. Phillips, and P. D. Warriss. 1999. Effect on young calves of a one-hour feeding stop during a 19-hour road journey. Vet. Rec. 144:687-692. https://doi .org/10.1136/vr.144.25.687.

Lava, M., B. Pardon, G. Schupbach, K. Keckeis, P. Deprez, A. Steiner, and M. Meylan. 2016. Effect of calf purchase and other herd-level risk factors on mortality, unwanted early slaughter and use of antimicrobial group treatments in Swiss veal calf operations. Prev. Vet. Med. 126:81-88. https://doi.org/10.1016/j.prevetmed.2016.01 .020 .

Lofstedt, J., I. R. Dohoo, and G. Duizer. 1999. Model to predict septicemia in diarrheic calves. J. Vet. Intern. Med. 13:81. https://doi .org/10.1892/0891-6640(1999)013<0081:mtpsid > 2.3.co;2.

Lomborg, S. R., L. R. Nielsen, P. M. H. Heegaard, and S. Jacobsen. 2008. Acute phase proteins in cattle after exposure to complex stress. Vet. Res. Commun. 32:575-582. https://doi.org/10.1007/ s11259-008-9057-7.

McGuirk, S. M. 2008. Disease management of dairy calves and heifers. Vet. Clin. North Am. Food Anim. Pract. 24:139-153. https://doi .org/10.1016/j.cvfa.2007.10.003.

McGuirk, S. M., and S. F. Peek. 2014. Timely diagnosis of dairy calf respiratory disease using a standardized scoring system. Anim. Health Res. Rev. 15:145-147. https://doi.org/10.1017/ S1466252314000267.

Mee, J. F. 2008. Prevalence and risk factors for dystocia in dairy cattle: A review. Vet. J. 176:93-101. https://doi.org/10.1016/j.tvjl .2007.12.032. 
Mohd Nor, N., W. Steeneveld, M. Mourits, and H. Hogeveen. 2012. Estimating the costs of rearing young dairy cattle in the Netherlands using a simulation model that accounts for uncertainty related to diseases. Prev. Vet. Med. 106:214-224. https://doi.org/10.1016/j .prevetmed.2012.03.004.

Murray, C. F., M. Windeyer, T. Duffield, D. Haley, D. Pearl, K Waalderbos, and K. Leslie. 2014. Associations of serum haptoglobin in newborn dairy calves with health, growth, and mortality up to 4 months of age. J. Dairy Sci. 97:7844-7855. https://doi.org/10 .3168/jds.2014-8465.

Ontsouka, E. C., C. Albrecht, and R. M. Bruckmaier. 2016. Invited review: Growth-promoting effects of colostrum in calves based on interaction with intestinal cell surface receptors and receptor-like transporters. J. Dairy Sci. 99:4111-4123. https://doi.org/10.3168/ jds.2015-9741.

Ortiz-Pelaez, A., D. Pritchard, D. Pfeiffer, E. Jones, P. Honeyman, and J. Mawdsley. 2008. Calf mortality as a welfare indicator on British cattle farms. Vet. J. 176:177-181. https://doi.org/10.1016/ j.tvjl.2007.02.006.

Otter, A., and G. Hateley. 2017. Blood cholesterol concentrations in dairy calves. Vet. Rec. 180:52. https://doi.org/10.1136/vr.j122.

Pardon, B., J. Alliët, R. Boone, S. Roelandt, B. Valgaeren, and P. Deprez. 2015. Prediction of respiratory disease and diarrhea in veal calves based on immunoglobulin levels and the serostatus for respiratory pathogens measured at arrival. Prev. Vet. Med. 120:169-176. https://doi.org/10.1016/j.prevetmed.2015.04.009.

Pardon, B., K. D. Bleecker, M. Hostens, J. Callens, J. Dewulf, and P. Deprez. 2012a. Longitudinal study on morbidity and mortality in white veal calves in Belgium. BMC Vet. Res. 8:26. https://doi.org/ 10.1186/1746-6148-8-26

Pardon, B., B. Catry, R. Boone, H. Theys, K. De Bleecker, J. Dewulf, and P. Deprez. 2014. Characteristics and challenges of the modern Belgian veal industry. Vlaams Diergeneeskd. Tijdschr. 83:155-163.

Pardon, B., B. Catry, J. Dewulf, D. Persoons, M. Hostens, K. D Bleecker, and P. Deprez. 2012b. Prospective study on quantitative and qualitative antimicrobial and anti-inflammatory drug use in white veal calves. J. Antimicrob. Chemother. 67:1027-1038. https://doi.org/10.1093/jac/dkr570.

Piccione, G., S. Casella, P. Pennisi, C. Giannetto, A. Costa, and G. Caola. 2010. Monitoring of physiological and blood parameters during perinatal and neonatal period in calves. Arq. Bras. Med. Vet. Zootec. 62:1-12. https://doi.org/10.1590/s0102 -09352010000100001.

Pigott, T. D. 2001. A review of methods for missing data. Educ. Res. Eval. 7:353-383. https://doi.org/10.1076/edre.7.4.353.8937.

Renaud, D. L., T. Duffield, S. LeBlanc, D. Haley, and D. Kelton. 2017. Management practices for male calves on Canadian dairy farms. J. Dairy Sci. 100:6862-6871. https://doi.org/10.3168/jds.2017-12750.
Renaud, D. L., T. Duffield, S. LeBlanc, D. Haley, and D. Kelton 2018. Risk factors associated with mortality at a milk-fed veal calf facility: A prospective cohort study. J. Dairy Sci. 101:2659-2668. https://doi.org/10.3168/jds.2017-13581.

Santos, R. L., R. M. Tsolis, A. J. Bäumler, and L. G. Adams. 2002. Hematologic and serum biochemical changes in Salmonella Typhimurium infected calves. Am. J. Vet. Res. 63:1145-1150. https://doi.org/10.2460/ajvr.2002.63.1145.

Skinner, J. G., R. Brown, and L. Roberts. 1991. Bovine haptoglobin response in clinically defined field conditions. Vet. Rec. 128:147149. https://doi.org/10.1136/vr.128.7.147.

Smith, B. 2009. Disorders and management of the neonate. Pages 284 to 285 in Large Animal Internal Medicine. 4th ed. Elsevier, St. Louis, MO.

Svensson, C., P. Liberg, and J. Hultgren. 2007. Evaluating the efficacy of serum haptoglobin concentration as an indicator of respiratorytract disease in dairy calves. Vet. J. 174:288-294. https://doi.org/ 10.1016/j.tvjl.2006.07.009.

Todd, C. G., K. Leslie, S. Millman, V. Bielmann, N. Anderson, J. Sargeant, and T. Devries. 2017. Clinical trial on the effects of a free-access acidified milk replacer feeding program on the health and growth of dairy replacement heifers and veal calves. J. Dairy Sci. 100:713-725. https://doi.org/10.3168/jds.2016-11401.

Trotz-Williams, L. A., K. Leslie, and A. Peregrine. 2008. Passive immunity in Ontario dairy calves and investigation of its association with calf management practices. J. Dairy Sci. 91:3840-3849. https://doi.org/10.3168/jds.2007-0898.

Weaver, D. M., J. W. Tyler, D. C. Vanmetre, D. E. Hostetler, and G. M. Barrington. 2000. Passive transfer of colostral immunoglobulins in calves. J. Vet. Intern. Med. 14:569 https://doi.org/10.1892/0891 $-6640(2000) 014<0569$ :ptocii $>2.3 . c 0 ; 2$.

Wilson, L. L., J. Smith, D. Smith, D. Swanson, T. Drake, D. Wolfgang, and E. Wheeler. 2000. Characteristics of veal calves upon arrival, at 28 and 84 days, and at the end of the production cycle. J. Dairy Sci. 83:843-854. https://doi.org/10.3168/jds.S0022-0302(00)74948 -4 .

Winder, C. B., D. F. Kelton, and T. F. Duffield. 2016. Mortality risk factors for calves entering a multi-location white veal farm in Ontario, Canada. J. Dairy Sci. 99:10174-10181. https://doi.org/10 $.3168 /$ jds.2016-11345.

Youden, W. J. 1950. Index for rating diagnostic tests. Cancer 3:32-35. https://doi.org/10.1002/1097-0142(1950)3:1<32:aidcncr $2820030106>3.0 . c 0 ; 2-3$. 